\title{
O BRDE E O CRESCIMENTO ECONÔMICO PARANAENSE: EVIDÊNCIAS EMPÍRICAS ${ }^{1}$
}

\section{THE BRDE AND ECONOMIC GROWTH OF PARANÁ: EMPIRICAL EVIDENCE}

\author{
Augusta Pelinski Raiher \\ Universidade Estadual de Ponta Grossa - PR - Brasil \\ Jandir Ferrara de Lima \\ Universidade Estadual do Oeste do Paraná - PR - Brasil
}

\begin{abstract}
Resumo: Este artigo analisa a importância do crédito fornecido pelo BRDE como indutor do crescimento econômico regional paranaense a partir de três ângulos: o crescimento do Produto Interno Bruto (PIB), o impacto na expansão do mercado externo via exportações e seu impacto na geração de emprego nas diferentes atividades econômicas. O espaço de análise foram as trinta e nove microrregiões paranaenses e o período de análise foi a primeira década do século XXI (2003 e 2009). Os resultados demonstraram que é extremamente relevante a participação dos recursos do BRDE na geração de emprego e renda no Estado do Paraná, ou seja, na indução do crescimento regional.
\end{abstract}

Palavras-chave: Crescimento econômico, Economia paranaense, Financiamentos.

Abstract: This paper analyzes the importance of credit provided by Bank of Regional Development of Southern (BRDE) in Paraná State, Brazil. to induce growth economic Paraná's regional from three angles: growth of the Gross Domestic Product (GDP), the impact on the expansion of foreign markets via exports and its impact on generation employment in different economic activities. The space of the analysis were the microregions of Paraná State and the period of analysis was the first decade of this century (2003 and 2009). The results demonstrated that is extremely relevant the participation of BRDE's resources in generating employment and income in the Paraná State, that is, in the induction of growth regional.

Keywords: Economic Growth, Economics Parana, Financing.

\section{Introdução}

Entre os instrumentos mais importantes para 0 desenvolvimento econômico, além da expansão da infraestrutura, da melhoria na qualificação profissional da população e da preservação dos recursos naturais, está a concessão de crédito aliada ao fomento de novos investimentos ou na manutenção e no fortalecimento da base produtiva local.

Infelizmente, nos últimos 20 anos, em função das políticas macroeconômicas implementadas no Brasil, a taxa de juro real tem permanecido elevada, tanto no crédito direto às empresas quanto aos consumidores, frente aos índices inflacionários e àquilo que é praticado nos países desenvolvidos. Além disso, os bancos comerciais têm linhas de crédito de curto prazo, dificultando ainda mais as necessidades de crédito de longo prazo e da captação para investimentos

\footnotetext{
${ }^{1}$ Este artigo foi premiado (terceiro lugar) no 7. ${ }^{\circ}$ Prêmio BRDE de Desenvolvimento. Seus resultados integram pesquisa financiada pelo Conselho Nacional de Desenvolvimento Cientifico e Tecnológico (CNPq) e pela Fundação Araucária (PR).
} 
de longa maturação. Diante dessa realidade, o Banco Regional de Desenvolvimento do Extremo Sul (BRDE) surge como um indutor das oportunidades de crédito, das melhores soluções de investimentos e como fomentador da expansão produtiva na Região Sul do Brasil.

O BRDE pertence aos Estados da Região Sul do Brasil e oferta crédito de médio e longo prazo. Como o BRDE é um intermediário financeiro, suas operações ativas, especialmente os empréstimos (crédito), estão lastreadas por obrigações junto a terceiros (depósitos, captações no mercado, repasses, entre outros), demonstrando a solvência da instituição. Nesse quesito, o BRDE era, no início do século $X X I$, a terceira instituição em termos de solvência, pois em suas operações ativas o Banco realiza, plenamente, a função de intermediação financeira, em que, a cada $R \$ 100,00$ em ativos, no BRDE $R \$ 71,00$ são créditos. Assim, dos bancos oficiais, o BRDE é o melhor colocado nesse critério (CUNHA, 2002).

Segundo o relatório da administração do BRDE (2010), somente no ano de 2010 as atividades desenvolvidas pelo Banco fomentaram investimentos na ordem de mais de $\mathrm{R} \$ 2$ bilhões. Esses recursos tiveram impacto direto na arrecadação de tributos, em torno de R\$236 milhões em ICMS para os Estados da Região Sul. Já o impacto no mercado de trabalho, em termos de empregos diretos, ficou na faixa de 10 mil postos de trabalho.

No Estado do Paraná, entre 2005 e 2010, as contratações totais do BRDE somaram mais de $R \$ 3,6$ bilhões, sendo que desses, $R \$ 1,9$ bilhões contratados entre 2009 e 2010, atendendo principalmente a produtores rurais de portes diferenciados e a micro e pequenas empresas (BRDE, 2010).

Frente a essa realidade, este artigo analisa a importância do crédito fornecido pelo BRDE como indutor do crescimento econômico regional paranaense a partir de três ângulos: o crescimento do Produto Interno Bruto (PIB), o impacto na expansão do mercado externo via exportações e seu impacto na geração de emprego nas diferentes atividades econômicas. O espaço de análise foram as trinta e nove microrregiões paranaenses e o período de análise foi a primeira década do século XXI (2003 a 2009), haja vista a disponibilidade das informações.

\section{Atuação e evolução dos recursos do BRDE no Paraná}

O BRDE tem um caráter duplo, pois de um lado é uma instituição financeira e de outro um agente do processo de crescimento ao fomentar a iniciativa de investimentos. O Banco possui um grande potencial como instituição para dar suporte aos investimentos essenciais e aos programas de desenvolvimento que estimulam o setor privado no Sul do Brasil (OLIVEIRA et al., 1989).

O BRDE não opera com recursos não reembolsáveis. Todos os financiamentos são reembolsáveis, tendo o financiamento para máquinas e equipamentos uma taxa de juros de 5,5\% a.a. fixa; para construção, reformas e giro, os recursos são taxados em média de 4,9\% a.a., acrescido da TJLP (6\% a.a.); os recursos destinados à agricultura variam de $2 \%$ a.a. - no caso de Pronaf - a $6,5 \%$ a.a. no financiamento aos agricultores e às cooperativas agroindustriais e de produção agropecuária (BRDE, 2012). 
Além das operações ligadas ao agronegócio, o BRDE tem feito investimentos substantivos em infraestrutura. Pelo Gráfico 01 se percebe que entre 2003 e 2009 houve um surto na expansão dos recursos destinados à infraestrutura. Após 2009, houve decréscimo nas contratações, mas os volumes continuaram expressivos. Cabe ressaltar que em 2008 houve o "estouro" da crise internacional e os repasses de recursos do BRDE devem ter atuado como efeito anticíclico em algumas regiões.

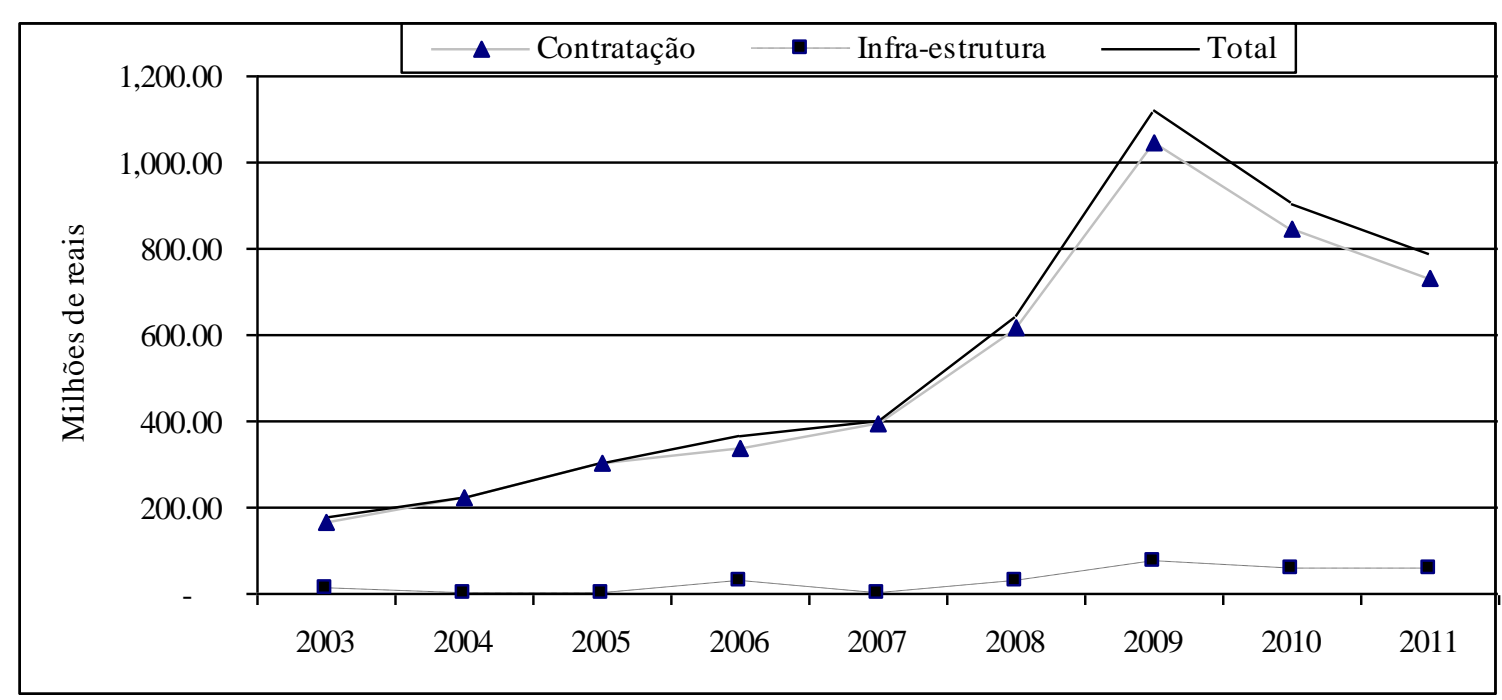

Gráfico 1. BRDE: Evolução dos Recursos destinados ao Paraná - infraestrutura e contratação - 2003 a 2011

Fonte: BRDE, 2012.

Outro aspecto que cabe ressaltar no caso paranaense, além da evolução dos recursos para infraestrutura, foi a distribuição dos recursos por setores econômicos. Em 2011, o "carro chefe" das operações de crédito era o setor primário e as atividades ligadas ao agronegócio. Porém, em 2009, o setor terciário fez uma tomada de recursos expressivos. Analisando todo o período (2003 a 2011), percebe-se que os três setores evoluíram positivamente, tendo períodos de oscilações, mas mantendo taxas de crescimento anuais expressivas: $26 \%$ para o setor terciário; 23\% para o primário; e 14\% para o secundário (Gráfico 2). 


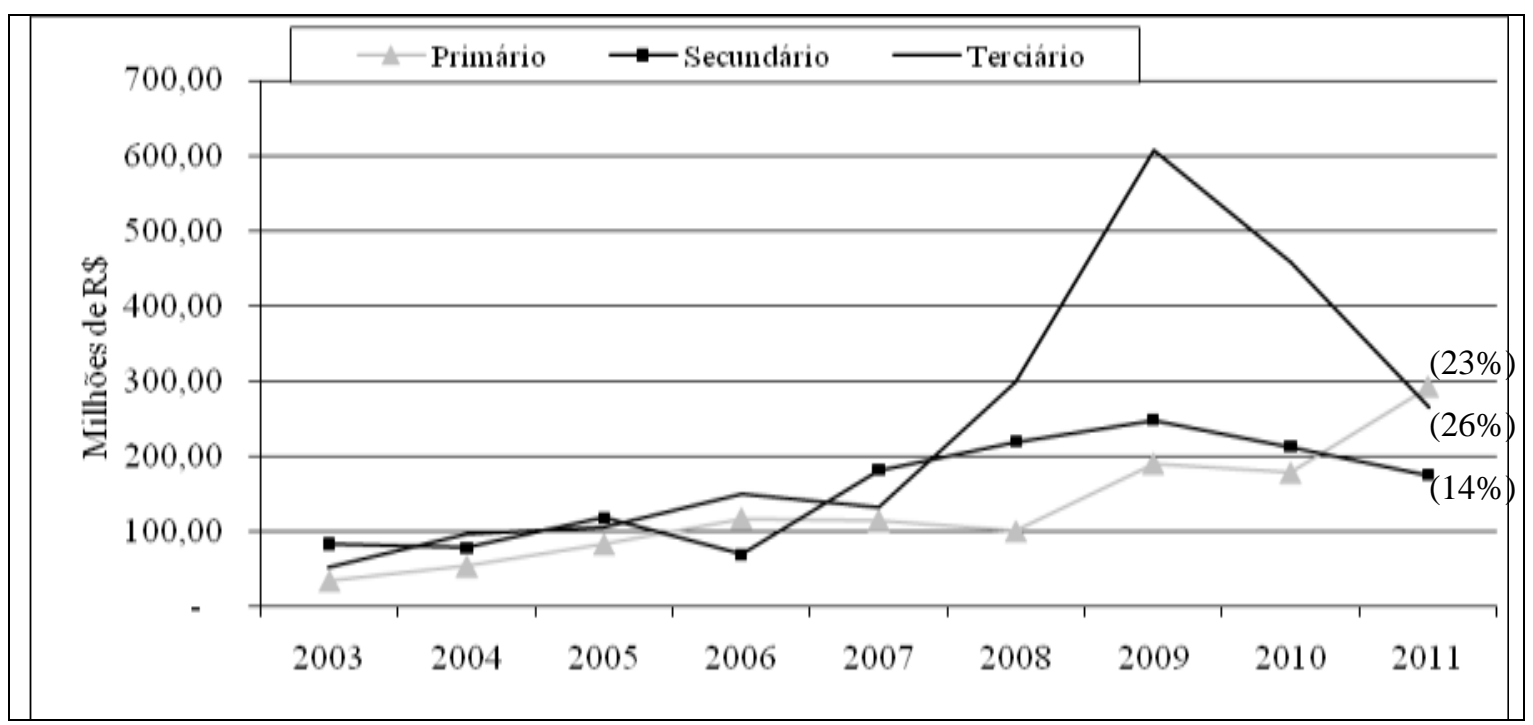

Gráfico 2. BRDE: Evolução e Taxa de crescimento anual dos Recursos destinados ao Paraná em contratação - Setores - 2003 a 2011

Fonte: BRDE, 2012.

No Paraná, o perfil da destinação dos recursos do BRDE demonstrou a necessidade crescente de suporte e financiamento ao setor primário. Cabe ressaltar que o Estado tem um papel importante nas atividades ligadas ao agronegócio e a ação das cooperativas agroindustriais tem sido cada vez mais significativa no fortalecimento da transformação agroalimentar no Estado. Dentre os gargalos que afligem $o$ agronegócio está a infraestrutura, o que explica o movimento semelhante das operações do BRDE no setor primário e na infraestrutura. Além disso, as mesorregiões paranaenses, com exceção da Mesorregião Metropolitana de Curitiba, têm sua dinâmica atrelada ao desempenho do setor primário e da transformação agroindustrial, deixando-as mais susceptíveis e fragilizadas aos problemas ambientais, aos problemas ligados à infraestrutura de escoamento de safras e as carências de créditos de custeio e comercialização.

Em 2003, a média dos recursos contratos do BRDE foi igual a $R \$$ 4.274.051,00 por microrregião, com uma discrepância dos valores em $R \$$ 6.920.214,00, tendo valor máximo igual a $R \$ 31.832 .062$. No ano de 2011, a média recebida entre as microrregiões se elevou, passando para $\mathrm{R} \$$ 16.724.639,00, com desvio padrão de 22.361.421,00, com valor máximo chegando a $\mathrm{R} \$ 80.654 .180,00$. Essa distribuição pode ser visualizada na Figura 01. 


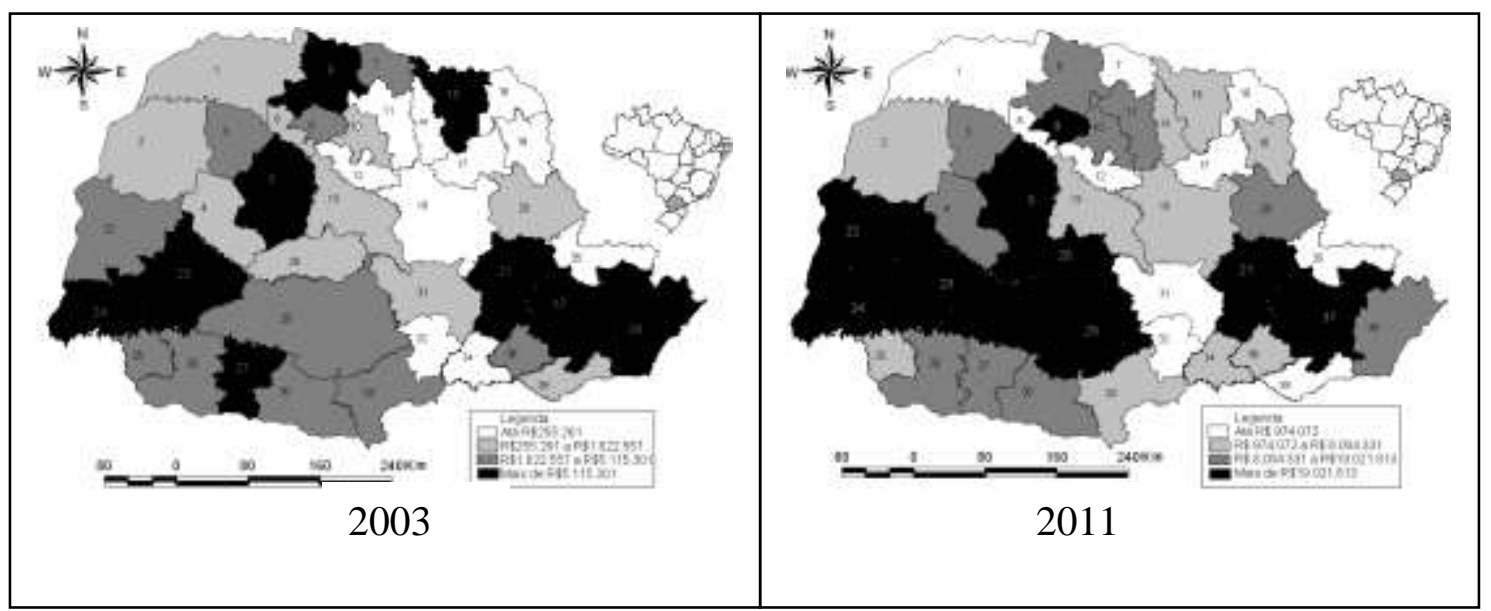

Figura 1. Distribuição dos recursos do BRDE entre as microrregiões do Paraná 2003 e 2011

Fonte: Dados originais do BRDE (2012), organizados pela pesquisa, com legenda das microrregiões no Anexo A.

Pela Figura 01 se observa que em 2003 havia um forte padrão de concentração dos recursos do BRDE nas mesorregiões do Oeste, Sudoeste e em algumas microrregiões da Região Metropolitana de Curitiba (RMC) e de Ponta Grossa. Em 2011, passa-se a ter uma concentração desses créditos principalmente no entorno da BR 277, tendo certa proximidade entre as microrregiões que receberam os maiores valores. Essa disposição dos valores em 2011 vem favorecer regiões de baixo dinamismo, como o Centro-Sul e parte do Centro do Paraná, áreas com grande carência de crédito e de investimentos de longo prazo.

\section{Elementos Teóricos e Metodológicos}

Esse tópico trata de elementos teóricos e metodológicos que explicam a relação entre crédito, no caso financiamentos e investimentos de longo prazo, em três elementos que são importantes para o dinamismo econômico de uma região, quais sejam: o crescimento econômico expresso como expansão do Produto Interno Bruto (PIB); as exportações regionais, que demonstram a inserção da economia regional no comércio internacional e sua capacidade de gerar excedentes; e, o emprego, expresso no aumento de postos de trabalho, o que indica também as oportunidades de renda da população.

\subsection{Os Recursos do BRDE e a Expansão do PIB Regional}

Para Schumpeter (1982), o desempenho econômico e com ele o crescimento econômico seriam estimulados por alguns fatores, quais sejam: as inovações, o crédito e a ação do empresário inovador. 
Dentre esses fatores, o crédito tem um papel primordial, pois ele é decisivo na promulgação das inovações ${ }^{2}$. Mesmo que os empresários não tenham capital suficiente ou que sua atividade não tenha gerado os recursos necessários para a expansão, ajustes ou lançamento de novos produtos, o crédito auxilia o empresário na execução de inovações. Ou seja, o crédito cria poder de compra tanto para o consumidor quanto para os empresários. No caso dos empresários, o financiamento de suas inovações e a elevação dos gastos das empresas conduz ao aumento dos dispêndios dos consumidores. Ao perceberem a elevação da demanda, as outras empresas também expandem suas produções, dando início ao boom do ciclo econômico. É neste sentido que o crédito torna-se essencial ao financiamento das inovações e, por consequência, ao processo de crescimento econômico de uma região.

Em geral, uma boa parcela dos investimentos requerem adiantamento de recursos financeiros (por meio do crédito), cujos correspondentes reais ainda não existem. Neste contexto, o investimento precede o crescimento e tem sua própria dinâmica: começa com a procura de uma oportunidade de lucro extranormal, e se espalha através da imitação. E é essa busca por novas oportunidades de investimento que fomenta a evolução do capitalismo (CASTRO, 2008).

O investimento é a decisão mais importante na dinâmica econômica e os bancos aparecem como peças fundamentais neste processo, entanto, é preciso ter fontes de recursos de longo prazo para viabilizá-lo. Antes de dar início a um novo investimento, o empresário necessita de uma quantia de recursos líquidos para enfrentar as suas necessidades imediatas de caixa; porém, nada garante que essa necessidade corresponderá a uma imediata abstenção de consumo (KEYNES, 1983). Nesse momento do tempo, nem o investimento nem a poupança existem, e o investimento é apenas uma intenção, ou seja, uma expectativa. Somente após ele ter sido efetivamente realizado, é que a renda e a poupança aparecerão através de um processo multiplicador estimulado pelo consumo, gerado tanto pelo investimento quanto pela renda dos trabalhadores. Daí vem a importância do financiamento, executados pelos bancos e pelas instituições de créditos (CASTRO, 2008).

Nessa ótica, o investimento é quem determina a poupança, dado que uma variação do investimento se traduz em elevação da renda (crescimento econômico) e, através dele, cresce a poupança e o emprego.

Além dessas abordagens, existem argumentos específicos no que se refere à intervenção do Estado no sistema financeiro, via atuação dos bancos públicos. Eles desempenham um papel essencial no desenvolvimento financeiro e no crescimento econômico dos países economicamente mais atrasados, tendo em vista que nesses países as instituições não são desenvolvidas o suficiente para induzir os bancos privados a financiar investimentos de longo-prazo. Dessa forma, o Estado deve criar o seu próprio banco para alavancar o crescimento econômico (GERSCHENKRON, 1973).

\footnotetext{
${ }^{2}$ Destacando que, para Schumpeter (1982), as inovações são: novas combinações dos meios de produção, introdução de um novo processo de produção, de um novo produto, a descoberta de uma nova forma de matéria-prima, de uma nova forma de organização comercial ou industrial, a abertura de um novo mercado e descoberta de uma nova fonte de matéria-prima.
} 
Um exemplo da importância dos bancos de desenvolvimento para o dinamismo econômico é o caso belga. Na Bélgica, a estrutura do sistema financeiro existente era insuficiente para fomentar a industrialização, principalmente pela dificuldade que as empresas tinham de acessar tais recursos. Com a criação da Société Générale em 1828, cujo status era de um banco privado, porém com uma participação relevante do governo em sua constituição ( $80 \%$ das ações), fomentou-se a disponibilidade de recursos para as indústrias, especialmente com recursos de longo prazo. Essa mudança, em conjunto com outras menores, conduziram a Bélgica a um período de crescimento econômico acelerado e industrialização intensa (MARTINS, 2012).

Esse exemplo demonstra a relevância do crédito para o crescimento econômico, justificando a verificação empírica quanto à importância do BRDE para o crescimento econômico das microrregiões paranaenses.

Para isso, organizou-se um modelo econométrico (1) do PIB de cada microrregião no período de 2003 a 2009 em função dos financiamentos do BRDE, do capital físico, do capital humano e da população.

$$
Y_{i t}=\alpha+b_{1} \operatorname{Cred}_{i t}+b_{2} K F_{i t}+b_{3} K H_{i t}+b_{4} P O P+\varepsilon
$$

Em que: $Y_{i t}$ é o PIB, a preço constante de 2005 (mil reais), tendo como fonte dados do Instituto de Pesquisa Econômica Aplicada (IPEA), disponível na sua base de dados IPEADATA (2012); Cred é o crédito fornecido pelo BRDE, com dados fornecidos pelo próprio BRDE, deflacionados pelo IGP-DI; KF é o capital físico, tendo como proxy o consumo de energia elétrica industrial (em Mwh), com dados do Instituto Paranaense de Desenvolvimento Econômico e Social (Ipardes), disponível no banco de dados estadual do Ipardes (2012); KHé o capital humano, usando a média de anos de estudo dos trabalhadores formais fornecidos pela Relação Anual de Informações Sociais (RAIS) do Ministério do Trabalho e Emprego; $P O P$ refere-se à população (em mil unidades), com dados do Ipardes; $i$ significa a $i$-ésima unidade transversal (microrregião); e té o tempo $t$ (ano).

A metodologia usada na estimação de (1) foi a de dados em painel, usando informações das 39 microrregiões, para os anos de 2003 a 2009 ${ }^{3}$, destacando que as variáveis de controle $K H, K F$ e $P O P$ referiram-se aos fatores enunciados pela literatura como determinantes do crescimento econômico (MANKIW, ROMER e WEIL, 1992; CANGUSSU; SALVATO; NAKABASHI, 2010, dentre outros).

Quando se usa dados em painel deve-se decidir entre estimação por Pooled O/s (PO), efeitos fixos (EF) e aleatórios (EA). Na estimação por $P O$, todos os coeficientes são constantes ao longo do tempo e entre os indivíduos. Por $E F$, assume-se que as diferenças entre as unidades de análise são consideradas como mudanças paramétricas da função de produção. E o método de estimação via $E A$ tem como suposição que a especificidade de cada unidade de análise é distribuída de forma aleatória.

\footnotetext{
${ }^{3}$ Como não se tinha disponível o valor do PIB para anos mais recentes, então o período de análise considerado foi 2003 até 2009.
} 
A principal motivação para a utilização da técnica de dados em painel é a possibilidade do controle do componente não observável (C). Conforme Wooldridge (2002), caso o mesmo não seja correlacionado com as variáveis explicativas do modelo, tanto o modelo Pooled quanto o modelo de Efeitos Aleatórios fornecem estimativas consistentes dos parâmetros, mas caso o componente não-observável (C) seja correlacionado com as variáveis explicativas da equação, esses modelos serão inconsistentes. Nessa situação, para se obter estimativas consistentes dos parâmetros, deve-se utilizar o modelo de Efeitos Fixos.

Nesse sentido, para decidir entre $E A$ e $P O$, utilizou-se o teste feito por Breusch e Pagan (Multiplicador de Lagrange para Efeitos Aleatórios), no qual a hipótese nula é a de que $\sigma_{u}^{2}=0$, não havendo diferença entre EA e Pooled Ols. $O$ resultado do teste foi $\chi^{2}=441$, rejeitando a hipótese nula e indicando que a metodologia de $E A$ é a mais adequada.

O próximo passo foi decidir entre efeito aleatório e fixo. Para isso, utilizou-se o teste de Hausman ${ }^{4}$, optando pelo método de efeitos aleatórios, dado que o valor de $\chi^{2}$ foi igual a 0,64, aceitando-se a hipótese nula.

Por fim, fizeram-se os testes de multicolinearidade (Fator de inflação da variância - FIV), heterocedasticidade (Breusch-Pagan) e autocorrelação (via o teste desenvolvido por Woodridge) para (1), identificando problemas de heterocedasticidade e de autocorrelação (resultados apresentado no Apêndice A). Por isso, (1) foi estimado por Feasible Generalizad Least Squares (FGLS), com a metodologia de Efeito Aleatório, visando corrigir tais problemas econométricos, usando o software Stata.

\subsection{BRDE e as Exportações}

A preocupação dos governos nacionais com o fluxo de comércio se dá por ele ser um importante componente da demanda efetiva de muitos segmentos da economia. Ainda que uma região não adote uma estratégia de desenvolvimento exclusivamente voltada para as exportações, o setor externo é visto como de grande relevância para o crescimento econômico, pois é um canal de escoamento de excedentes econômicos. Além do efeito sobre as contas externas, ao fortalecer a conta corrente do Balanço de Pagamentos, as exportações geram externalidades positivas para as indústrias e, consequentemente, para a geração de emprego e renda de uma região. Deter um setor exportador forte é considerado de grande importância para o dinamismo econômico regional (CATERMOL e LAUTENSCHLAGER, 2010).

Particularmente, na abordagem keynesiana, a demanda de uma região depende do consumo, do investimento e dos gastos governamentais, acrescendo

\footnotetext{
${ }^{4} \mathrm{O}$ teste de Hausman é usado para escolher entre o modelo de efeito fixo ou aleatório. De acordo Gujarati (2006), a hipótese nula subjacente a este teste é que os estimadores do modelo de efeitos fixos e do modelo de correção dos erros (efeitos aleatórios) não diferem substancialmente, destacando que tal teste tem uma distribuição de "qui quadrado" assintótica. Se a hipótese nula for rejeitada, a conclusão é que o modelo de correção de erros não é adequado e que é preferível empregar o modelo de efeitos fixos.
} 
na análise o setor externo. Nesta ótica, a exportação é o único componente autônomo da demanda agregada, e por isso os teóricos consideram a restrição no Balanço de Pagamentos (BP) como o principal fator limitante do crescimento econômico, em que somente por meio da expansão das exportações seria possível aumentar a taxa de crescimento da economia, sem deteriorar o Balanço de Pagamentos (THIRLWALL,1979). A relação das exportações no crescimento econômico fica mais clara quando se observa a equação de equilíbrio da renda, na sua forma mais simples:

$$
Y=C+I+G+(X-M)
$$

Em que, $\mathrm{Y}=$ Produto real da economia ou demanda agregada; $\mathrm{C}=$ consumo; I = investimentos; $G=$ gastos do governo; $X=$ exportações; $M=$ importações.

Pela equação se observa que as importações têm um efeito inversamente proporcional na expansão do produto, pois implica uma entrada de bens e serviços que poderiam estar sendo produzidos internamente na economia. Num sentido inverso, as exportações implicam conquista de mercados e expansão das atividades produtivas internas para atender a uma demanda adicional além da demanda doméstica. Ou seja, quanto mais exportações, maior a presença da economia do mercado inter-regional, e consequentemente maiores são os estímulos ao aumento da produção, gerando oportunidades de renda e emprego para a população.

O crescimento da região está intimamente ligado ao sucesso de suas exportações, podendo ocorrer como resultado da melhoria da posição das exportações existentes, relativamente às áreas competitivas, ou como resultado do desenvolvimento de novos produtos. Quando o fortalecimento da base econômica se dá em função do comércio exterior, ela reflete vantagens comparativas regionais. A medida que as regiões crescem ampliando sua base de exportações geram-se economias externas, estimulando a competitividade dos bens exportados e até mesmo dos demais produtos locais (devido às externalidades) (VOLLET e DION, 2001).

Assim, na literatura econômica, diversos autores defendem a fomentação das exportações para se ter um dinamismo econômico sustentável ao longo do tempo. E um dos elementos dito importantes para alavancar as exportações são os financiamentos.

O sistema de financiamento aparece como aspecto vital para a política de promoção às exportações de qualquer região. Como reflexo da elevada influência que os financiamentos exercem sobre as exportações, pode-se afirmar que, em alguns casos, a mercadoria exportável em si assume apenas posição de simples subproduto. A existência ou não de financiamento é que define, em muitos casos, a concretização do negócio. No caso do financiamento que não é específico para a exportação, esse adiantamento de recursos financeiros tendem a fomentar a produção e, se o produto que recebeu o crédito for competitivo internacionalmente, se induzem as exportações da região (BLUMENSCHEIN, 2002). 
Assim, sem considerar financiamentos específicos do BRDE para as exportações paranaenses, mas levando em conta todos os recursos que o mesmo forneceu para cada microrregião, é que se analisou se esses créditos influenciaram, ou não, as exportações do Paraná. Para isso, usaram-se dados referentes às 39 microrregiões no período de 2003 a 2009, estimando a equação (3), a qual tem como variável dependente as exportações e como variável independente os créditos do BRDE, o câmbio e o PIB mundial.

$$
\ln X_{i t}=\alpha+b_{1} \ln \text { Cred }_{i t}+b_{2} \ln C B_{i t}+b_{3} \text { PIBm }_{i t}+\varepsilon
$$

Em que: $X$ são as exportações (em dólares), deflacionadas pelo IPC americano, com ano base de 2005, sendo os dados do sistema AliceWeb do Ministério do Desenvolvimento, Indústria e Comércio; $C B$ é a taxa efetiva real do câmbio do Brasil $(2005=100)$, como fonte sendo o IPEADATA; PIBm é o PIB mundial (em dólares), a preços constantes de 2005, também obtido do IPEADATA; Cred é o crédito fornecido pelo $B R D E$, com dados repassados pelo próprio BRDE, deflacionados pelo IGP-DI; In é o logaritmo; i significa a i-ésima unidade transversal (microrregião); e: té o tempo $t$ (ano).

A metodologia usada na estimação de (3) foi a de dados em painel, usando informações das 39 microrregiões, para os anos de 2003 a 2009, destacando que as variáveis de controle CB e PIBm referiram-se aos fatores enunciados pela literatura como determinantes da Exportação (MONTEIRO, 2002, dentre outros).

Conforme se fez na estimação (1), para se decidir entre Efeitos aleatórios e Pooled Ols, utilizou-se o teste feito por Breusch e Pagan (Multiplicador de Lagrange para Efeitos Aleatórios). O resultado foi $\chi^{2}=380$, rejeitando a hipótese nula e indicando que a metodologia de $E A$ é a mais adequada. Na sequência, a decisão entre Efeito Aleatório e Fixo foi realizada pelo teste de Hausman, optando pelo método de efeitos aleatórios, dado que o valor de $\chi^{2}$ foi igual a 0,40 , aceitando-se a hipótese nula.

Por fim, fizeram-se os testes de multicolinearidade (Fator de inflação da variância - FIV), heterocedasticidade (Breusch-Pagan) e autocorrelação (via o teste desenvolvido por Woodridge), identificando problemas de heterocedasticidade e de autocorrelação (resultados apresentados no Apêndice A). Por isso, a equação (3) foi estimada por Feasible Generalizad Least Squares (FGLS), com a metodologia de $E A$, visando corrigir tais problemas econométricos, usando o software Stata.

\subsection{O Efeito dos Financiamentos do BRDE e o nível de Emprego}

O modelo clássico da economia tem dentre seus postulados que o mercado de trabalho determina os salários reais e o nível de emprego, o qual, via função de produção, determina a oferta de bens e serviços dessa economia. Porém, a taxa de desemprego pode variar sem que haja qualquer mudança nos salários reais. 
Então o que determina o nível de emprego da economia? A resposta está no principio da demanda efetiva (KEYNES, 1983).

A figura 2 ilustra o princípio da demanda efetiva, na qual Z é a oferta global resultante do emprego de $\mathbf{N}$ homens e $\mathbf{D}$ é a função de procura global. $\mathrm{O}$ volume de emprego fica estabelecido no encontro das funções "procura global" e "oferta global". A procura efetiva é definida como o valor de D no ponto de intercessão da função da procura global com a da oferta global. No momento que $\mathbf{D}$ for maior que $\mathbf{Z}$ há um estímulo para o aumento do emprego e a produção de novos bens, até o momento no qual $Z=D$.

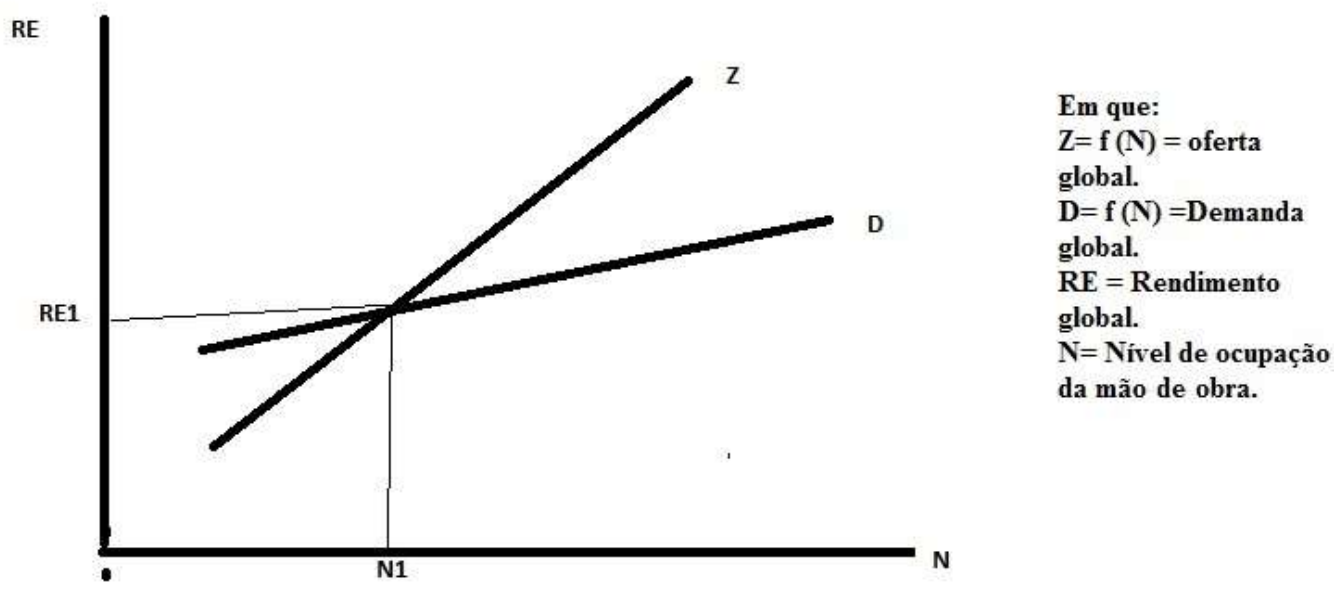

Figura 2. Princípio da demanda efetiva.

Fonte: Keynes, 1983.

No modelo clássico em qualquer volume de produção e de emprego, a função de oferta global e a função de procura global seriam iguais. O pleno emprego seria facilmente atingido, pois a concorrência entre os empresários levaria sempre a um aumento do emprego, até que a oferta global desse fosse inelástica. Nesse ponto, um aumento da procura efetiva não levaria a um aumento da produção.

A justificativa para a criação de empregos reside na existência de investimentos que absorvam os excedentes de produção, mantendo ou até mesmo aumentando a receita dos empresários, estimulando-os a oferta de novos postos de trabalho. Então, dada a propensão a consumir da população demonstrada pela sua demanda efetiva, os empresários ampliarão ou reduzirão o emprego, através do nível de investimento. O incentivo ao investimento depende da relação entre a escala da eficiência marginal do capital e o complexo das taxas de juros inerentes aos empréstimos de prazos e riscos diversos. $O$ nível de emprego é compatível com o equilíbrio quando a renda ou emprego for igual ao montante de consumo ou demanda efetiva mais os investimentos. Caso contrário, a procura global e a oferta global seriam diferentes. Esse nível de emprego pode estar abaixo, mas não superior ao pleno emprego. Esse fato atesta a relação 
mútua entre a propensão marginal a consumir e os incentivos para investir (KEYNES, 1983).

O nível de emprego é determinado então pela propensão marginal a consumir mais o investimento, que determina também o nível dos salários reais. Caso a propensão marginal a consumir e o montante do investimento resultem numa insuficiência da demanda efetiva, o volume do emprego cai até ficar abaixo da oferta de mão de obra disposta a trabalhar pelo salário real em vigor. Ocorreria assim uma situação de desemprego involuntário. Esse fato explica o paradoxo da "pobreza em meio à abundância", pois a insuficiência de procura efetiva não permite à economia de chegar ao seu ponto de pleno-emprego (KEYNES, 2002).

Há a tendência de se alargar a distância entre o produto real e o produto potencial quanto mais rica for a região. Uma região pobre tenderá a consumir quase toda a sua produção. Por isso, um pequeno investimento garante níveis elevados de emprego. Porém, se os empresários não têm recursos suficientes para investir, apesar das possibilidades de negócios, cabe ao mercado de crédito e às instituições de fomento fornecerem os recursos necessários. Quanto mais crédito disponível com taxas de juros adequadas às necessidades dos empresários e da população, maior o acesso ao consumo e aos investimentos, gerando novos postos de trabalho e, consequentemente, expandindo o Produto Interno Bruto e as condições de vida da população (KEYNES, 1983 e 2002).

Assim, o dinamismo do mercado de trabalho é importante tanto como indicador quanto para o desenvolvimento de uma região. Nesse sentido que se analisa se os financiamentos concedidos pelo BRDE influenciam a geração de emprego no Paraná (4).

$$
\ln E_{i t}=\alpha+b_{1} \ln \operatorname{Cred}_{i t}+b_{2} \ln S R_{i t}+\varepsilon
$$

Em que $E$ refere-se ao emprego (dados da RAIS); $S R$ é o salário médio, deflacionado pelo IGP-DI, sendo 2005=100, também dados da RAIS; Cred é o crédito fornecido pelo $B R D E$, com dados repassados pelo próprio BRDE, deflacionados pelo IGP-DI; In é o logaritmo; i significa a i-ésima unidade transversal (atividades econômicas "CNAE grupo") e; té o tempo $t$ (ano).

A metodologia usada na estimação de (4) foi a de dados em painel, usando informações das 282 atividades econômicas do Paraná, descritos em Cadastro Nacional de Atividades Econômicas (CNAE), aqui expressa como "CNAE grupo", para os anos de 2003 a 2009, destacando que se usou como variável de controle o "salário médio" de cada atividade em cada ano.

Conforme se fez na estimação (1), para se decidir entre Efeitos aleatórios e Pooled Ols, utilizou-se o teste feito por Breusch e Pagan, obtendo um $\chi^{2}$ igual a 461, rejeitando a hipótese nula e indicando que a metodologia de EA é a mais adequada do que a de Pooled Ols. A decisão entre Efeito Aleatório e Fixo foi realizada pelo teste de Hausman, optando pelo método de efeitos aleatórios, dado que o valor de $\chi^{2}$ foi igual a 0,45, aceitando-se a hipótese nula. 
Destaca-se que foram feitos os testes econométricos visando validar os resultados obtidos (Fator de inflação da variância para a multicolinearidade, Breusch-Pagan para a heterocedasticidade e teste desenvolvido por Woodridge para a autocorrelação), não identificando nenhum problema econométrico (resultados apresentados no Apêndice A).

\section{BRDE e o crescimento regional paranaense}

Conforme exposto nos tópicos iniciais deste artigo, a concessão de financiamentos, especialmente de longo prazo, favorece o dinamismo econômico de uma região. Seu impacto pode afetar diferentes variáveis, dentre elas a geração de emprego, renda, produção, exportações, entre outras. Todas essas variáveis estão, de uma forma ou de outra, interligadas, promulgando seus efeitos em cadeia.

Ao mesmo tempo, quando considerado o período de 2003 a 2011, percebeu-se que o BRDE vem elevando o montante de recursos fornecidos ao Paraná, com uma taxa de crescimento anual de aproximadamente $22 \%$.

Dessa forma, se há relação entre o financiamento fornecido pelo BRDE e determinadas variáveis-chave do crescimento econômico, então a sua atuação no Paraná está sendo importante para o seu crescimento desse Estado.

Nesse sentido, visando identificar a sua influência no crescimento econômico é que se estimou o impacto dos financiamentos do BRDE no PIB regional, cujos resultados estão expostos na Tabela 1.

Tabela 1. Resultados econométricos da influência de algumas variáveis sobre PIB das microrregiões do Paraná -2003 a 2009

\begin{tabular}{l|c|c|c|c|c|}
\hline \multirow{2}{*}{$\begin{array}{l}\text { Variável } \\
\text { Dependente }\end{array}$} & \multicolumn{4}{|c|}{ Variáveis explicativas } \\
\cline { 3 - 6 } & & $\mathrm{KH}$ & Cred & KF & POP \\
\hline Constante & & 28.753 & 0,003 & 1,012 & 6.532 \\
& 351.477 & $(2,42)^{*}$ & $(4,17)^{*}$ & $(4,87)^{*}$ & $(31,49)^{*}$ \\
\hline
\end{tabular}

Fonte: Resultado da Pesquisa

Nota* Significativo a um nível de significância de 5\%. Y é o PIB (mil reais); Cred é o crédito fornecido pelo BRDE (R\$); KF é o capital físico (Mwh); KH é o capital humano (ano), e; POP é a população (mil habitantes).

Nos resultados da pesquisa observou-se que as variáveis de controle, capital físico, humano e a população apresentaram resultados condizentes com a teoria econômica (sinal e todas foram significativas a um nível de significância de $5 \%$ ), na qual um aumento de $1 \mathrm{Mwh}$ no consumo de energia elétrica industrial (proxy do capital físico) eleva em R\$1,01 mil o PIB das microrregiões do Estado. Já o acréscimo de 1 ano na escolaridade média dos paranaenses (proxy do capital humano) acresce o PIB em R\$28.753,00 mil, ceteris paribus. É importante destacar que o capital humano é inserido em diferentes modelos (como o de Lucas (1988), Romer (1990), Nelson e Phelps (1966)) como sendo importante para a 
fomentação do crescimento econômico. E isso se dá basicamente pela sua ação direta - via elevação da produtividade e da criação de novas tecnologias- e indiretamente - pela difusão de tecnologias já existentes. Assim, diferentes autores, como Nakabashi (2005), conseguiram evidenciar empiricamente essa relevância do capital humano para o crescimento econômico, corroborando com os resultados aqui encontrados.

Considerando a população, tal variável veio com o sinal positivo, indicando que seu aumento em uma unidade eleva em aproximadamente $\mathrm{R} \$$ $6.532,00$ o PIB. Nakabashi (2005), analisando o crescimento de alguns países selecionados, também encontrou um coeficiente positivo para essa variável, argumentando que provavelmente o dinamismo populacional estaria sendo determinado endogenamente nesses países, acarretando, consequentemente, em crescimento econômico.

No caso dos créditos do $B R D E$, um aumento de $R \$ 1,00$ nos seus valores conduz a um acréscimo de $R \$ 3,00$ no $P I B$, exercendo uma influência positiva e significativa, a um nível de significância de 5\%. Como no ano de 2011 a média dos financiamentos do BRDE fornecidos para as microrregiões foi de aproximadamente $R \$ 16.724 .639,00$, então a sua estimativa de contribuição para a formação do PIB em cada microrregião, para aquele ano, é de $R \$ 50.173,00$ mil (valores médios). Ou seja, existe uma influência importante do BRDE no crescimento econômico das microrregiões paranaenses.

No entanto, essa relação que foi obtida entre os créditos do BRDE e o crescimento econômico não necessariamente indica o sentido da causalidade, ou seja, esses financiamentos poderiam estar se dirigindo para microrregiões que já vêm apresentando um dinamismo econômico mais forte. Por isso, com o intuito de testar a existência de um efeito a priori desses financiamentos no dinamismo econômico, rodou-se novamente o modelo (1), contudo não considerando o financiamento no período " $t$ ", mas sim no período " $t-1$ ". Como resultado obteve-se um coeficiente igual a 0,001 para o financiamento "t-1", sendo significativo a um nível de significância de 5\%, o que legitima a afirmativa quanto ao efeito do BRDE no crescimento econômico. No trabalho apresentado por La Porta et al. (2002), esse efeito positivo dos créditos públicos é identificado, especialmente quando se trata de países menos desenvolvidos, confirmando os resultado aqui encontrados.

No caso da relação exportações e financiamentos do BRDE, cabe ressaltar que a demanda externa é entendida como um dos motores do crescimento econômico, estando intimamente ligada com o desempenho econômico da região. Em síntese, o seu melhoramento gera maior renda interna, elevando o consumo local, o que acarreta novamente uma elevação da produção, agora voltada para a demanda interna, com atração de novas empresas e/ou ampliação das existentes e, consequentemente, melhorando a renda, seguindo-se o círculo virtuoso. Assim, uma melhor posição da região frente às exportações é extremamente importante para conduzir o crescimento econômico. E um dos fatores-chave para promover as exportações é o financiamento (BLUMENSCHEIN, 2002).

No caso do Paraná, os dados da estimativa da relação financiamentos e exportações, apresentadas na Tabela 2, demonstraram que dentre as variáveis comumente ditas relevante para o crescimento das exportações - taxa de câmbio e 
PIB mundial -, apenas a segunda se demonstrou significativa a $5 \%$. Isso significa que uma elevação da renda mundial em 1\% conduz a um acréscimo de 4,17\% nas exportações das microrregiões paranaenses. A taxa de câmbio veio com o sinal condizente com a teoria econômica, porém não foi significativa a 5\%. Além da renda internacional, outro elemento que se mostrou influente foi o crédito fornecido pelo BRDE, no qual o aumento de $1 \%$ nos financiamentos conduziu a uma elevação de $0,056 \%$ nas exportações. Como o crescimento médio anual dos créditos do BRDE no período de 2003-2009 foi de 22\%, então a sua importância estimada para as exportações foi de aproximadamente 1,23\% ao ano. Ou seja, as linhas de crédito e financiamento do BRDE têm se destinado a produtos competitivos internacionalmente, contribuído para a inserção da economia paranaense na economia mundial, num efeito positivo sobre o conjunto da economia regional estadual.

Tabela 2. Resultados econométricos da influência de algumas variáveis sobre as Exportações das microrregiões do Paraná -2003 a 2009

\begin{tabular}{l|c|c|c|c}
\hline Variável & & \multicolumn{3}{|c}{ Variáveis explicativas } \\
\cline { 3 - 5 } Dependente & Constante & Ln Cred & Ln PIBm & Ln CB \\
\hline Ln X & 129,57 & 0,056 & 4,168 & 1,105 \\
& $(2,89)^{*}$ & $(2,99)^{*}$ & $(3,38)^{*}$ & $(1,57)$ \\
\hline
\end{tabular}

Fonte: Resultado da Pesquisa

Nota* Significativo a um nível de significância de $5 \%$. $X$ são as exportações; $C B$ é a taxa efetiva real do câmbio do Brasil; PIBm é o PIB mundial; Cred é o crédito fornecido pelo BRDE,e; In é o logaritmo.

Tanto o crescimento do PIB como da exportação pode estar favorecendo apenas uma parcela da sociedade, pois a inserção de pacotes tecnológicos pode estimular a produtividade em contrapartida à geração de empregos. Por isso, a análise quanto ao emprego se torna relevante. No crescimento das duas variáveis PIB e Exportação - em geral se tem a elevação no número de postos de trabalho, porém pode ser que a grande massa de riqueza gerada se concentre apenas para alguns agentes, não elevando proporcionalmente o número de emprego quando comparado ao crescimento que se tem no PIB e no fluxo comercial. Como o financiamento do BRDE afeta essas duas variáveis, e como os fundos do BRDE são recursos públicos, o ideal, então, é que ele esteja beneficiando a população de forma mais homogênea possível.

Assim, identificar se os recursos do BRDE estão gerando emprego numa magnitude significativa se tornou importante para analisar a sua influência no dinamismo econômico regional do Paraná. E é isso que é apresentado na Tabela 3 , via a estimativa da influência dos financiamentos do BRDE na geração de empregos. Observa-se que um aumento do salário de determinado setor em $1 \%$ tende a diminuir o emprego do mesmo setor em 0,03\%, sendo significativo a $5 \%$; ao passo que se o financiamento fornecido elevar em $1 \%$ estima-se que o percentual de postos de trabalho cresça em $0,16 \%$, ao nível de significância de $5 \%$. 
Tabela 3. Resultados econométricos da influência de algumas variáveis sobre o emprego das atividades econômicas do Paraná -2003 a 2009

\begin{tabular}{l|c|c|c}
\hline Variável Dependente & \multirow{2}{*}{ Constante } & Ln Cred & Ln Sr \\
\cline { 2 - 4 } & 7,119 & 0,162 & $-0,0295$ \\
\hline Ln E & $(22,79)^{*}$ & $(1,97)^{*}$ & $(-2,47)^{*}$ \\
\hline
\end{tabular}

Fonte: Resultado da Pesquisa

Nota* Significativo a um nível de significância de 5\%. E refere-se ao emprego; SR é o salário médio; Cred é o crédito fornecido pelo BRDE, e; In é o logaritmo;

Os resultados demonstraram que é extremamente relevante a participação dos recursos do BRDE na geração de emprego e renda no Estado do Paraná, ou seja, no crescimento econômico regional estadual.

\subsection{Impacto do BRDE no Crescimento Econômico das Microrregióes Paranaenses}

Conforme exposto nos aspectos teóricos e metodológicos, a literatura econômica em geral enfatiza o papel dos financiamentos no fomento do desempenho econômico de uma região. No caso paranaense, conseguiu-se captar a relação positiva entre os recursos investidos pelo BRDE em cada microrregião e o seu crescimento econômico, bem como seu efeito nas exportações e na geração de emprego nas diversas atividades econômicas do Estado. Dessa forma, com os resultados apresentados na Tabela 1, estimaram-se o impacto dos recursos do BRDE, acumulados no período de 2003 a 2009, sobre o PIB de cada microrregião paranaense também nesse período (Figura 3).

Com os resultados da pesquisa observou-se que a contribuição dos financiamentos do BRDE para o PIB variou de $R \$ 675$ mil até $R \$ 1.364$ milhões. As mesorregiões mais beneficiadas com a ação do BRDE foram: o Oeste, o Sudoeste, - Centro Oriental e a Ocidental paranaense. Em contrapartida, as mesorregiões que o impacto foi menor foram o Sudeste, Noroeste e Norte Pioneiro. 


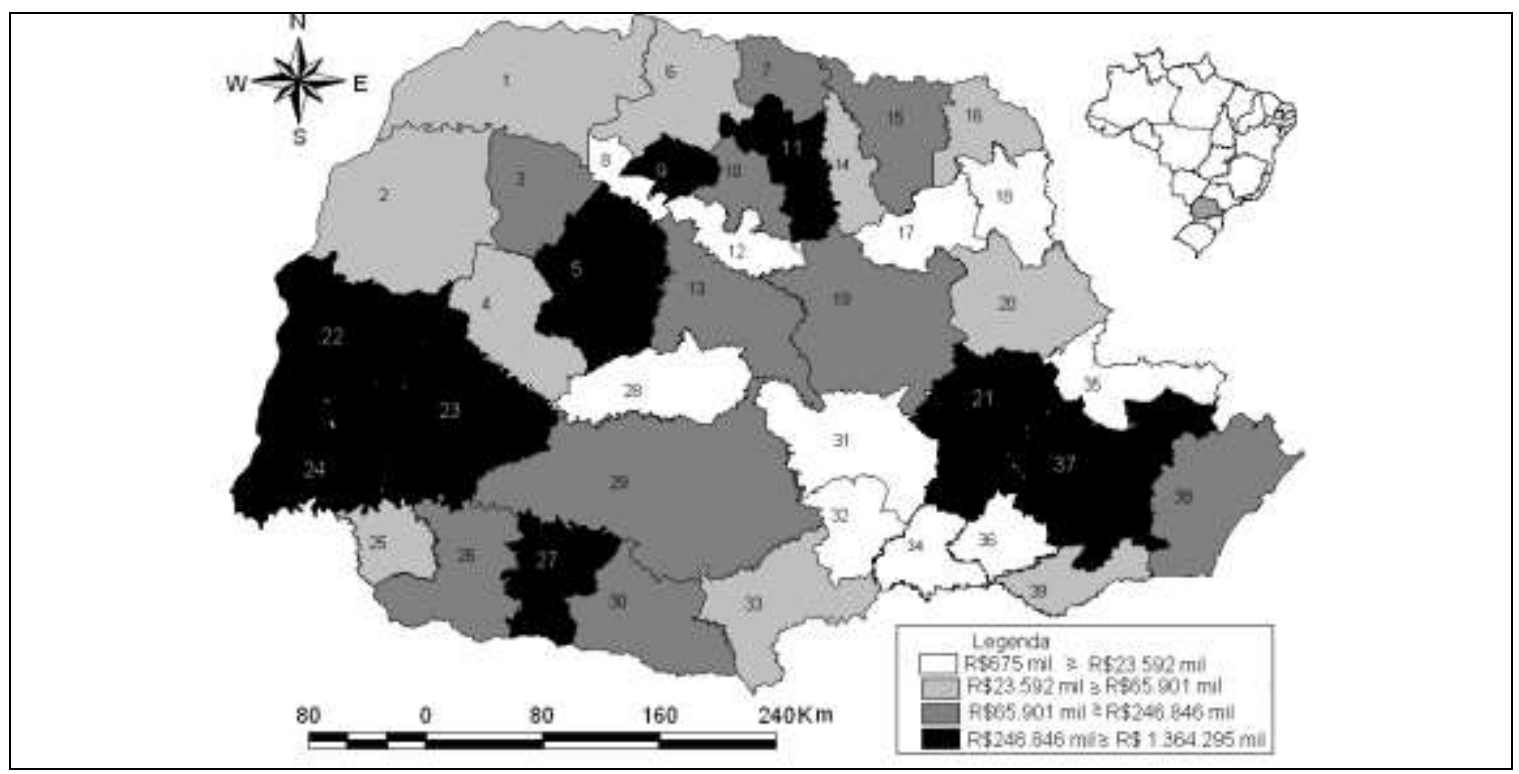

Figura 3. BRDE: Estimativa do impacto dos recursos nas microrregiões do Paraná Valores acumulados 2003-2009 em R\$.

Fonte: Resultado da Pesquisa a partir de dados do BRDE, 2012, com legenda das microrregiões no anexo $\mathrm{A}$.

Ao se comparar a distribuição de recursos do BRDE com o desempenho do PIB de 2003 (Figuras 3 e 4), percebe-se uma significativa correlação positiva ${ }^{5}$ entre as variáveis. As microrregiões que tinham um desempenho econômico relevante em 2003 foram exatamente as que, em geral, receberam maior impacto dos financiamentos do BRDE (tendo em vista que foram as que mais receberam esses recursos).

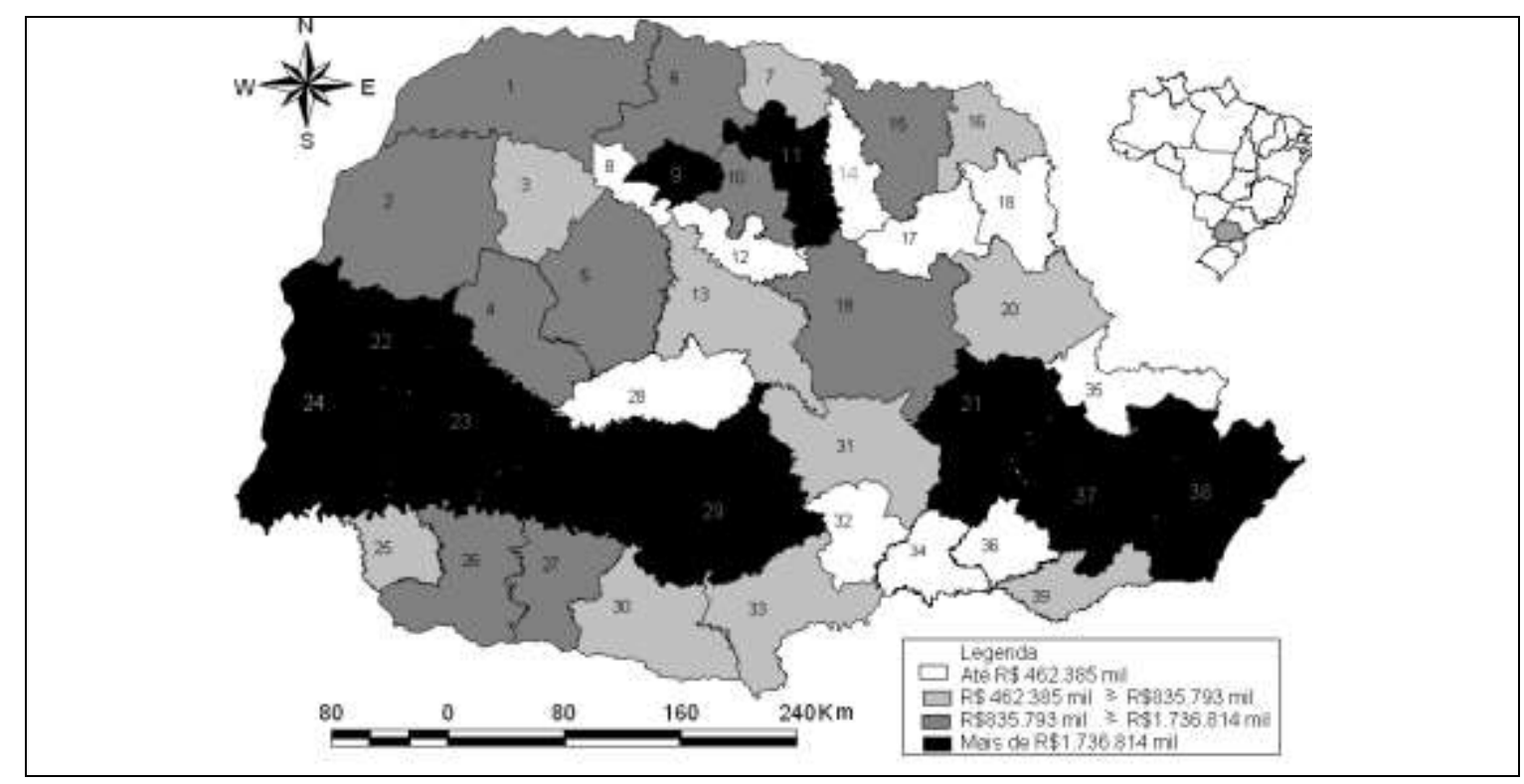

Figura 4. PIB das microrregiões do Paraná em $\mathrm{R} \$-2003$

Fonte: IPEADATA, 2012, com legenda das microrregiões no anexo A.

\footnotetext{
${ }^{5}$ Correlação de Spearman igual a 0.85 , significativa a um nível de $1 \%$.
} 
Nesse sentido, conseguiu-se identificar um efeito positivo dos financiamentos do BRDE para o crescimento econômico e como esse crescimento não tem uma distribuição homogênea ao longo de todo Estado. Daí, a importância de priorizar tais recursos principalmente para as regiões de menor PIB. Assim, a ação do BRDE se tornará, cada vez mais, um fomento para o dinamismo das economias mais retardatárias, tornando o Estado do Paraná mais equitativo quanto ao crescimento econômico.

\section{CONCLUSÃO}

O objetivo deste artigo foi analisar a importância do crédito fornecido pelo BRDE como indutor do crescimento econômico regional paranaense a partir de três ângulos: o crescimento do Produto Interno Bruto (PIB); o impacto na expansão do mercado externo; e seu impacto na geração de emprego nas diferentes atividades econômicas. O espaço de análise foram as trinta e nove microrregiões paranaenses e o período de análise foi a primeira década do século XXI (2003 e 2009), sendo a metodologia utilizada a análise econométrica com o uso de dados em painel.

Os resultados da análise demonstraram que as variáveis capital físico, capital humano e população apresentaram resultados condizentes com a teoria econômica. Nesse caso, o aumento de 1 Mwh no consumo de energia elétrica industrial (capital físico) eleva em R\$1,012 mil o PIB das microrregiões do Paraná. O aumento de um habitante conduz a um acréscimo de $\mathrm{R} \$ 6.532$ no PIB. Já o acréscimo de 1 ano na escolaridade média dos paranaenses (capital humano) eleva em $\mathrm{R} \$ 28.753$ mil o PIB regional paranaense. Ou seja, investimentos e financiamentos que têm impacto direto sobre a qualificação e consumo da população têm um efeito rápido no ciclo econômico e, consequentemente, no crescimento econômico regional. Essa afirmação foi confirmada ao se analisar a expansão nos valores dos créditos do $B R D E$, cujo aumento na faixa de $R \$ 1,00$ conduz a um acréscimo de R\$3,00 no PIB. Como no ano de 2011 a média dos financiamentos do BRDE, fornecidos para as microrregiões foi de aproximadamente $\mathrm{R} \$ 16.724 .639,00$. Então a sua estimativa de contribuição para a formação do PIB em cada microrregião, para aquele ano, é de $\mathrm{R} \$ 50.173,00$ mil. Ou seja, existe uma influência importante do BRDE no crescimento econômico das microrregiões paranaenses.

No caso da relação exportações e financiamentos do $B R D E$, os resultados demonstraram que uma elevação da renda mundial em $1 \%$ conduz a um acréscimo de $4,17 \%$ nas exportações das microrregiões paranaenses. Além da demanda internacional, outro elemento que se mostrou influente foi o crédito fornecido pelo BRDE, no qual o aumento de $1 \%$ nos financiamentos conduz a uma elevação de 0,056\% nas exportações. Como ente 2003-2009, o crescimento médio anual dos créditos do BRDE foi de $22 \%$, então a sua importância estimada para as exportações foi de aproximadamente 1,23\% ao ano. Ou seja, as linhas de crédito e financiamento do BRDE têm contribuído para a inserção da economia regional paranaense na economia mundial. 
Os resultados demonstraram que é extremamente relevante a participação dos recursos do BRDE na geração de emprego e renda no Estado do Paraná, ou seja, na indução do crescimento e regional. Com isso, cabe fortalecer a atuação do BRDE, ampliando as linhas e o acesso ao crédito. Da mesma forma, cabe aos Estados cotistas do BRDE usá-lo como instrumento de desenvolvimento regional, ampliando a oferta de recursos para custeio de exportações, de infraestrutura e de inovação principalmente nas microrregiões menos dinâmicas do Estado. Portanto, o BRDE pode e deve ser utilizado como instrumento do crescimento econômico regional, principalmente como suporte às políticas públicas de emprego e renda.

Deve-se destacar que todos os resultados tiveram como espaço de análise apenas o Estado do Paraná, com suas particularidades, considerando um período de tempo curto. Além disso, as estimativas obtidas estão sujeitas às condições impostas pelo modelo funcional que foi proposto. Dessa forma, a dimensão dos coeficientes pode variar e se tornar mais preciso se a amostra puder ser expandida para toda a região Sul, considerando um intervalo de tempo maior, podendo se analisar de forma mais precisa a relação de causalidade existente entre os créditos do BRDE e o crescimento regional.

\section{REFERÊNCIAS}

BLUMENSCHEIN, F.N; . De LEON, F. L.L. Uma análise do desempenho e da segmentação do sistema de crédito à exportação no Brasil. Brasília:

BNDES/FUNCEX/FGV, 2002. Disponível em: <http://www.ipea.gov.br/ppp/index.php/PPP/article/viewFile/145/147>. Acesso em abril de 2012.

BRDE. Dados avulsos. Curitiba: BRDE, 2012. Disponível em <http://www.brde.com.br>. Acesso em abril de 2012.

BRDE. Relatório da administração 2010. Porto Alegre: BRDE, 2010.

CANGUSSU, R.C.; SALVATO, M.; NAKABASHI, L., Uma análise do capital humano sobre o nível de renda dos estados brasileiros: MRW versus Mincer. Estudos Econômicos, v. 40, n. 1, 2010.

CASTRO, L. B. Financiamento e crescimento: uma visão geral da literatura e posicionamento no debate. Revista do BNDES, Rio de Janeiro, v. 14, n. 29, p. 277 308, jun. 2008.

CATERMOL, F.; LAUTENSCHLAGER, A. O crédito oficial à exportação no contexto de crise: experiências internacionais e o BNDES. Revista do BNDES, n. 34, 2010.

CUNHA, A. M. O BRDE e o sistema bancário brasileiro: Uma análise comparada. Indicadores econômicos FEE. Porto Alegre, v. 30., nº 02, p. 191-220, 2002.

GERSCHENKRON, A. El atraso economico en su perspectiva historica. Barcelona: Ediciones Ariel, 1973. 
GUJARATI, D.N. Econometria Básica. Rio de Janeiro: Elsevier, 2006.

IPARDES. Banco de dados estadual. Curitiba: Ipardes, 2012. Disponível em <http://www.ipardes.pr.gov.br>. Acesso em abril de 2012.

IPEADATA. Dados avulsos. Brasília: IPEA, 2012. Disponível em <http://www.ipeadata.gov.br>. Acesso em maio de2012

KEYNES, J.M. La pauvreté dans l'abondance. Paris: Gallimard, 2002.

A teoria geral do emprego, do juro e da moeda. (os economistas). São Paulo: Nova Cultural, 1983.

La Porta, R; Lopez-de-Silanes, F; Shleifer, A. Government ownership of Banks. National Bureau of Economic Research, Working Paper n. 7620, 2002.

LUCAS, R.E. On the mechanics of economic development. Journal of Monetary Economics, v. 22, p. 3-42, 1988.

MANKIW, N.G; ROMER, D.; WEIL, D.N. A contribution to the empirics of economic growth. The Quarterly journal of economics, v.107, n.2, p.407-437, 1992.

MARTINS, N.M. Bancos de desenvolvimento e desenvolvimento financeiro: uma avaliação do caso brasileiro entre 2000 e 2011. 2012. Dissertação (Programa de Pós-Graduação em Economia). Instituto de Economia da Universidade Federal do Rio de Janeiro, Rio de Janeiro, 2012.

MONTEIRO, S. A. B. Redes neurais artificiais, análise de sensibilidade e o comportamento de funçôes de comércio exterior do Brasil. Tese apresentada a Universidade Federal do Rio Grande do Sul. Faculdade de Ciências Econômicas. Programa de Pós-Graduação em Economia, 2002.

NAKABASHI, L. Três ensaios sobre o capital humano e renda por trabalhador. Belo Horizonte, 2005. Tese (doutorado em Economia) - Centro de Desenvolvimento e Planejamento Regional, Universidade Federal de Minas Gerais.

NELSON, R.; PHELPS, E. Investment in humans, technological diffusion, and economic growth. The American Economic Review, v.56, p. 69-75, mar., 1966.

OLIVEIRA, A. R.; MARTINI, D. L.; SILVA, P. R. O desenvolvimento em crise: a liquidação do BRDE. Ensaios FEE. Porto Alegre, v. 10, nº 01, p. 03-11, 1989.

RAIS. Dados estatísticos da Rais/Caged. Brasília: Ministério do Trabalho e Emprego, 2012. Disponível em <http://www.emprego.gov.br>. Acesso em abril de 2012. 
ROMER, P.M. Endogenous Technological Change. Journal of Political Economy, v. 98, n.5, p.71-99,1990.

SCHUMPETER, J. A. (1911). A Teoria do Desenvolvimento Econômico. São Paulo: Abril Cultural, 1982.

THIRLWALL, A. The balance of payments constrain as an explanation of international growth rates differences. Banca Nazionale del Lavoro Quarterly Review, v. 128, 1979.

VOLLET, D. ; DION, Y. Les apports potentiels des modèles de la base économique pour guider la décision politique . Revue d'Économie Régionale et Urbaine (RERU), Bordeaux, n², p.179-196, 2001.

WOOLDRIDGE, J. M. Econometric Analysis of Cross-Section and Panel Data. Massachusetts Institute of Technology, 2002.

Submetido em 07/08/2012

Aprovado em 30/06/2014

\section{Sobre os autores}

Augusta Pelinski Raiher

Doutora em Economia pela UFRGS. Profa. Adjunta do Departamento de Economia da UEPG.

Endereço: Praça Santos Andrade, n. ${ }^{\circ}$ 01, Bloco D/Sala 215 - Centro. CEP 84010-919 - Ponta Grossa - PR - Brasil.

E-mail: apelinski@gmail.com.com

\section{Jandir Ferrara de Lima}

Doutor em Desenvolvimento Regional (Ph.D.) pela Université du Québec (UQAC)/Canadá. Professor do Programa de Pós-graduação em Desenvolvimento Regional e Agronegócio (Mestrado e Doutorado) da UNIOESTE. Bolsista e pesquisador do CNPq. Pesquisador da Fundação Aracuária (PR).

Endereço: Rua da Falculdade, 645, Jd Santa Maria. CEP 85903000 - Toledo - PR - Brasil.

Email: Jandir.Lima@unioeste.br. 
APÊNDICE A: Resultados Econométricos das estimativas (1), (2) e (3).

\begin{tabular}{|c|c|c|c|}
\hline Estimativa & FIV (multicolinearidade) & Autocorrelação & Heterocedasticidade \\
\hline Do PIB (1) & $\begin{array}{l}\mathrm{KF}=2,28 \\
\mathrm{Cred}=1,31 \\
\mathrm{KH}=1,13 \\
\mathrm{POP}=2,62\end{array}$ & $32,34^{*}$ & $44,47^{*}$ \\
\hline Da Exportação (2) & $\begin{array}{l}\text { Ln } C b=7,86 \\
\text { Ln } P I B=7,84 \\
\text { Ln Cred }=1,02\end{array}$ & $380^{*}$ & $152^{*}$ \\
\hline Do Emprego (3) & $\begin{array}{l}\text { Ln Cred }=1,01 \\
\text { Ln } S I=1,01\end{array}$ & $0,071^{\text {ns }}$ & $0,76^{\text {ns }}$ \\
\hline
\end{tabular}

Fonte: Resultado da pesquisa

Nota: * rejeitou-se $\mathrm{H}_{0}$ ns significa que não se rejeitou $\mathrm{H}_{0}$.

ANEXO A: Número e nomes das microrregióes paranaenses das figuras 2, 3 e 4

\begin{tabular}{cc|c|c}
\hline Número & Microrregião & Número & Microrregião \\
\hline 10 & Apucarana & 16 & Jacarezinho \\
14 & Assaí & 20 & Jaguariaíva \\
6 & Astorga & 36 & Lapa \\
5 & Campo Mourão & 11 & Londrina \\
25 & Capanema & 9 & Maringá \\
23 & Cascavel & 30 & Palmas \\
35 & Cerro Azul & 1 & Paranaguá \\
3 & Cianorte & 27 & Paranavaí \\
15 & Cornélio Procópio & 28 & Pato Branco \\
37 & Curitiba & 21 & Pitanga \\
12 & Faxinal & 7 & Ponta Grossa \\
8 & Floraí & 31 & Porecatu \\
24 & Foz do Iguaçu & 39 & Prudentópolis \\
26 & Francisco Beltrão & 34 & Rio Negro \\
4 & Goioerê & 19 & São Mateus do Sul \\
29 & Guarapuava & 22 & Telêmaco Borba \\
17 & Ibaiti & 2 & Toledo \\
32 & Irati & 33 & Umuarama \\
13 & Ivaiporã & 18 & União da Vitória \\
& & & Wenceslau Braz \\
\hline
\end{tabular}

Fonte: Ipardes (2012) 